\title{
Lugares, Discursos e Subjetividades nas Organizações: o caso de uma prisão
}

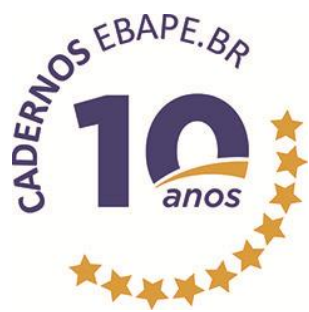

\author{
Places, Discourses and Subjectivities in Organizations: the case of a \\ prision
}

Clara Luísa Oliveira Silva ${ }^{1}$

Luiz Alex Silva Saraiva ${ }^{2}$

\section{Resumo}

Nesse artigo se procurou analisar a articulação dos elementos concretos e/ou simbólicos do(s) lugar(es) que os sujeitos ocupam na organização com os aspectos relacionados ao modo como esses sujeitos produzem sentidos sobre si mesmos e sobre suas relações sociais. De maneira geral, a pesquisa aborda a problemática da produção (e controle) da subjetividade nas organizações. A organização em análise, uma prisão, foi abordada qualitativamente mediante um estudo de caso baseado em 15 entrevistas semiestruturadas que, após serem gravadas e transcritas, foram analisadas pela análise francesa do discurso. Identificou-se que o(s) lugar(es) no lugar organização, além de referência física, se referem a uma construção social relacionada a uma condição formal, a artefatos e a significações. O regime semiaberto, por exemplo, ao converter a frágil liberdade em ameaça ao "conforto" sólido da instituição total, fortalece a organização em detrimento do sujeito. Ajustar-se ao contexto organizacional corresponde, assim, a um tipo de contrapartida pela segurança proporcionada, e algo que se deve agradecer, uma espécie de doutrinamento que aproxima as prisões das demais organizações.

Palavras-chave: Lugares. Discursos. Subjetividades. Prisões.

\begin{abstract}
In this paper we have tried to analyze the articulation of concrete and/or symbolic elements of place(s) occupied by subjects in organization with related aspects of ways these subjects make sense about theirselves and their social relationships. In general, the research addresses the problem of production (and control) of subjectivity in organizations. The analyzed organization, a prison, was approached qualitatively through a case study based on 15 semi structured interviews which, after being recorded and transcripted, were analyzed using French discourse analysis. We have identified the places in organization place, beyond a physical reference, refers to a social construction related, simultaneously, to a formal condition, to artefacts and significations. Semi open conditions, for example, transform fragile freedom in a threat to solid "comfort" of total institution, make organization strong, and the subject, weak. To adjust to organizational context is a kind of answer to safety, something to be thankful, a kind of indoctrination which approach prisons and other organizations.
\end{abstract}

Keywords: Places. Discourses. Subjectivities. Prisons.

Artigo submetido em 25 de fevereiro de 2013 e aceito para publicação em 18 de julho de 2013.

${ }^{1}$ Mestre em Administração pela Universidade Federal de Minas Gerais, tendo sido Bolsista da FAPEMIG durante o Mestrado; Professora Substituta da Universidade Federal de Ouro Preto. Endereço: Rua Padre Pedro Evangelista, 255, apt. 201, Coração Eucarístico, CEP 30535-490, Belo Horizonte - MG, Brasil. E-mail: claralosilva@yahoo.com.br

2 Doutor em Administração pela Universidade Federal de Minas Gerais; Professor Adjunto do Departamento de Ciências Administrativas e do Centro de Pós-Graduação e Pesquisas em Administração da Faculdade de Ciências Econômicas da Universidade Federal de Minas Gerais. Endereço: Av. Antonio Carlos, 6627, Universidade Federal de Minas Gerais, Faculdade de Ciências Econômicas, Pampulha, CEP 31270-901, Belo Horizonte - MG, Brasil. E-mail: saraiva@face.ufmg.br 


\section{Introdução}

A organização é um lugar. Entende-se que o lugar não se reduz a uma dimensão objetiva, a uma mera ideia de localização geográfica no meio de traçados geométricos aparentemente justificados por uma funcionalidade dos projetos arquitetônicos. O significado do lugar está relacionado à perspectiva de produção social. Nesse sentido, mais do que uma construção de tijolos mobiliada com cadeiras, mesas, e máquinas, a organização, enquanto lugar, é uma construção social, "edificada" e "mobiliada" por sentimentos, interpretações, memórias dos sujeitos que lá estabelecem (ou estabeleceram) suas ações (LEFEBVRE, 1991).

No lugar, inscrevem-se e reproduzem-se funções materiais e valores sociais (FISCHER, 1994), predominando uma dialética entre elementos materiais e de construção simbólica (RICHARDSON e JENSEN, 2003). E tais elementos são justificados por linguagens e de discursos - velados ou explícitos que constroem posições e ações dos sujeitos ou mesmo subjetividades (CHIA, 2000; HARDY, PALMER e PHILLIPS, 2000; FOUCAULT, 2004). O objetivo nesse estudo foi analisar a articulação dos elementos concretos e/ou simbólicos do(s) lugar(es) que os sujeitos ocupam na organização com os aspectos relacionados ao modo como esses sujeitos produzem sentidos sobre si mesmos e sobre suas relações sociais.

Com base em uma perspectiva qualitativa (GODOY, 1995; FLICK, 2004; CHIZZOTTI, 2005), foi desenvolvido um estudo de caso (STAKE, 1978; EISENHARDT, 1989; YIN, 2005) em uma unidade feminina de uma organização prisional que, mediante o discurso da "recuperação", busca (re)construir a realidade dos sujeitos que cumprem suas devidas penas privativas de liberdade. $\mathrm{O}$ discurso da possibilidade de reinserção social se mostra tão imperativo que, nessa organização, classificada como um centro de ressocialização, "recuperando" é a palavra "correta" para designar os que cumprem pena nos regimes fechado, semiaberto e aberto.

Encerrado no objetivo deste trabalho está a problemática da produção de subjetividade (e controle) nas organizações, especialmente nas instituições totais, uma espacialidade social em que as pessoas, geralmente em grande quantidade, vivem "fechadas", separadas da sociedade mais ampla, tendo sua vida "administrada" por considerável período de tempo. E, nesse tempo, o conjunto de processos, práticas e procedimentos organizacionais, ao se calcar na violência da autonomia do ato, faz das instituições totais verdadeiras "[...] estufas para mudar as pessoas; [...] um experimento natural sobre o que se pode fazer ao eu" (GOFFMAN, 1961, p. 22).

$\mathrm{O}$ artigo está dividido em seis partes, incluindo esta breve introdução. Na segunda parte, são apresentadas reflexões teóricas sobre as possíveis relações entre lugares, discursos e subjetividades. Compõe a terceira parte do trabalho uma explanação sobre o discurso que "legitima" os elementos concretos e simbólicos do lugar "prisão". Em seguida explicitam-se as escolhas metodológicas do estudo. E, após a quinta seção, "apresentação e análise dos dados", são expostas as considerações finais.

\section{Lugares, discursos e subjetividades nas organizações: aproximações possíveis}

"A organização repousa sobre um modelo de racionalidade da qual podemos dizer que racionaliza os lugares neutralizando as qualidades sensíveis do espaço" (FISCHER, 1994, p. 90), isto é: o espaço ${ }^{3}$ é "o espelho da organização". Para o autor, muitos dos princípios desse modelo são concretos e configuram, por exemplo, os

${ }^{3}$ Alguns autores distinguem as palavras "espaço" e "lugar". Espaço seria apenas uma realidade de traçados e formas geométricas, ao passo que lugar estaria ligado aos significados e sentidos atribuídos pelos sujeitos a esses traçados e formas geométricas. Fischer (1994) não esclarece essa diferença, usando a palavra espaço no sentido de meio social, espaço social. Nesse artigo, adota-se "lugar", sendo equivalente a expressão "espaço social". 
espaços "dividido", "imposto" e "controlado". Diz-se, por exemplo, que as organizações constituem espaços divididos tendo em vista sua unidade distinta em relação ao meio social mais amplo, possibilitando, inclusive, comparações entre o que está "dentro" ou "fora". Além disso, o ambiente organizacional é fragmentado de acordo com a especialização das atividades, isto é, localizações, distâncias e relações de vizinhos, por exemplo, repousam sobre a monofuncionalidade (FISCHER, 1994).

De certa forma, o espaço organizacional é imposto. Um sistema de atribuição de lugares permite, muitas vezes, mediante uma escala social rigorosa, "fixar" categorias de sujeitos em locais definidos, designando os lugares acessíveis e os proibidos. O lugar é imposto na medida em que cada sujeito é instalado em dada espacialidade sem que a tenha escolhido. E essa imposição, justificada pelo "adequado funcionamento" dos processos cotidianos, acaba por refletir o sistema hierárquico, que inscreve os estatutos e funções convergentes à natureza do espaço que o sujeito ocupa (ou o lugar que lhe foi imposto). Dessa maneira, “[...] o espaço organizacional, como todos os outros espaços sociais ordenados, é um espaço político na medida em que ele é o vetor das orientações que o poder lhe imprime" (FISCHER, 1994, p. 91).

O jogo dos espaços na organização revela também a estrutura de vigilância idealizada para se ter o controle sobre aquele que "lá" ou "aqui" está. O espaço, assim, é controlado, mediatizando o funcionamento hierárquico por meio de arrumações que orientam as vias de circulação e os canais formais de comunicação (FISCHER, 1994). Por esta ótica, as organizações, como espaços sociais ou lugares, podem ser entendidas como conjuntos de discursos não usados apenas para descrever uma coisa ou situação, mas também para produzir coisas, situações, realidades e identidades sociais. Discursos que modelam hábitos de pensamentos ao justificar objetos particulares de conhecimento, posições e ações dos sujeitos (CHIA, 2000; HARDY, PALMER e PHILLIPS, 2000), ao legitimar a existência da própria organização, como se percebe nas prisões e no discurso da reinserção social dos encarcerados.

As organizações são construídas "na" e "pela" linguagem, sendo esta relacionada, por um lado, aos aspectos de "conteúdo", na medida em que é usada para descrever os diferentes fenômenos organizacionais, e, por outro, atrelada ao "contexto", à existência de textos (falados e escritos) situados em uma dimensão espaçotemporal, bem como a uma concepção que demarca os discursos hegemônicos e marginalizados (BOJE, OSWICK e FORD, 2004).

Estar em um lugar específico, que emerge de uma dialética entre elementos materiais e simbólicos (RICHARDSON e JENSEN, 2003), significa a possibilidade de exercer ou não determinada prática discursiva $^{4}$ (FOUCAULT, 2004), implica a possibilidade de os sujeitos utilizarem ou não o discurso como um "recurso estratégico" na tentativa de imporem suas intenções (HARDY, PALMER e PHILLIPS, 2000). Quem enuncia um discurso parte de uma formação discursiva específica, de uma matriz histórica de sentido, na qual os conceitos e as escolhas temáticas, por exemplo, se definem sob certa regularidade (FOUCAULT, 2004).

A reflexão sobre o sujeito enquanto produtor de discursos destaca a questão da ideologia, que, para Van Dijk (1998), se refere aos sistemas de crenças, ideias e valores que direcionam e legitimam as ações dos sujeitos e, por decorrência, dos grupos de que fazem parte. Fiorin (2006) apresenta ideologia como um conjunto de ideias e representações utilizado no propósito de explicar e justificar as condições de vida e as relações sociais do ser humano. O autor afirma que "a cada formação ideológica corresponde uma formação discursiva, que é um conjunto de temas e de figuras que materializa uma dada visão de mundo. [...] É com essa formação discursiva que o homem constrói seus discursos".

4 "Conjunto de regras anônimas, históricas, sempre determinadas no tempo e no espaço, que definiram, em uma dada época e para uma determinada área social, econômica, geográfica e linguística, as condições de exercício da função enunciativa" (FOUCAULT, 2004, p. 132). 
Se as organizações, aqui, incluindo as prisões, são consideradas padrões de discursos simbólicos (SMIRCICH, 1983), construídos quando das interações humanas, de que forma estes discursos concorrem para a construção de indivíduos como sujeitos que pertencem a uma determinada coletividade (ou determinada categoria)? Em outras palavras, de qual forma tais discursos mobilizam subjetividades, ou normalizam modos de o sujeito ser e se relacionar?

O lugar, composto por discursos velados e explícitos, produz e reproduz modos de ser humano ou experiências subjetivas, potencializando ou não a ação individual e social. Pode ser comparado a um tipo de palco no qual o sujeito reflete sobre sua "presença" em um lugar (ou quem sabe, em lugar nenhum) no mundo (FISCHER, 1994; VALADARES, 2000; HALFORD e LEONARD, 2006). Isto é, o lugar produz subjetividades, engendra produções de sentidos, para usar o termo de González Rey ${ }^{5}$ (2005).

Essa ideia se alinha ao que Guattari e Rolnik (1986) denominaram de subjetividade capitalística, um tipo de subjetividade produzida pelos ditos sistemas maquínicos que estão associados ao modelo de consumo em massa no capitalismo ou às estruturas totalitárias dos Estados. Grosso modo, o processo de subjetivação capitalística equivaleria a uma imposição de determinada ordem que incide sobre as ações, os gestos, os esquemas de pensamento, as montagens de sentido, a modelização de instâncias intra-subjetivas.

Em suas apreciações sobre o que tange à produção de subjetividade nas organizações, Enriquez (1997) chama a atenção para o exercício do controle sobre o modo de pensar, isto é, inculca-se a ideia de que é preciso pensar sempre no "bem" das organizações ou, em outros termos, pensar sempre nas maneiras de alcançar os objetivos determinados nesses espaços sociais. A lógica que é ainda reforçada é a que se refere aos processos de identificação, na medida em que o indivíduo idealiza os espaços sociais organizativos, se identifica com os mesmos, tornando-se uma espécie de "serviçal voluntário" que descobre o gozo na submissão. Procura-se instaurar, nas organizações, uma significação de que o indivíduo é respeitado, é valorizado. Dizendo de outra forma, nesses espaços, exigem-se "[...] indivíduos que se querem sujeitos (mas que, de fato, são alienados) de seu destino e agentes da história" (ENRIQUEZ, 1997, p. 25). O que ocorre, porém, é o aprisionamento desses indivíduos nas identificações heroicas, o que os faz se comportarem como seres prontos, delimitados por um padrão de heroi.

Todavia, vislumbram-se os modos de o sujeito exercer seu potencial (re)criador diante das estruturas e processos organizacionais de cunho normalizador.

A linha de argumentação neste artigo considera que as subjetividades ou produções de sentidos (GONZÁLEZ REY, 2005) também constituem o lugar. Isso fica mais claro, por exemplo, quando dos processos de apropriação, caracterizados pela dominação, de caráter físico ou psicológico, do sujeito sobre o lugar. A apropriação permite que ele se afirme (ou se reafirme) sobre dado lugar, fazendo desse, algo único e próprio (FISCHER, 1994).

Para Guattari e Rolnik (1986), os movimentos que atuam de maneira a questionar esse sistema capitalístico de produção de subjetividade, a resistir aos processos que conduzem à serialização da subjetividade, a construir modos originais e singulares de sensibilidade e de relação com o outro, são todos movimentos que os autores denominam como "processos de singularização" ou ainda "revolução molecular". Ao pressupor a recusa de todos os modos de codificação e de manipulação previamente estabelecidos, a ocorrência dos processos de singularização desencadeia uma espécie de reapropriação de territórios subjetivos. Reapropriação no sentido de as referências teóricas e práticas do indivíduo não se prenderem a um poder global, nos níveis econômico, técnico ou do saber. Ao contrário, fiando-se no princípio de autonomia, tais

${ }^{5}$ Conforme González Rey (2005), o sujeito produz sentidos quando faz registros emocionais associados aos significados e às necessidades ao longo de sua história. A subjetividade se afiguraria como uma produção de sentidos histórica e contextualmente localizada, que, por seu turno, não se circunscreve ao campo individual, nem ao social, pois encerra o que é constituído nos dois campos dentro de um mesmo sistema (GONZÁLEZ REY, 2005). 
referências serão criadas pelos indivíduos depois que estes realizarem uma leitura de sua própria situação, compreendendo sua singularização existencial. É, portanto, no decurso dos processos de singularização, que aquele indivíduo padronizado se transforma em sujeito singular (GUATTARI e ROLNIK, 1986). Tais elaborações podem ser compreendidas, inclusive, a partir da noção de processos de subjetificação (BERGSTRÖM e KNIGHTS, 2006), em que, na interação entre a agência e os discursos constituídos, ocorreria, de um lado, a aceitação de alguns determinantes estruturais, considerando, todavia, que a subjetividade não se constituiria de maneira homogênea e controlável, mas múltipla.

Tomando por base o aporte teórico de González Rey (2003), pode-se dizer que o sujeito está implicado nas possibilidades de ruptura dos limites impostos nos espaços sociais. Sendo capaz de gerar, em diferentes momentos (e espaços socais) de sua trajetória, espaços próprios de subjetivação, o sujeito está além das normas sociais e, portanto, dos processos (ou políticas, práticas) que se chamaria de totalizantes ou de mobilizadores de modos de ser e se relacionar. Quando se afirma que o sujeito está além das normas sociais, quer se ressaltar o fato de que, embora o sujeito se constitua a partir de suas condições de vida social, não se torna efeito linear de nenhuma dessas condições. Isso porque produz sentidos subjetivos alternativos aos princípios e normas que limitam a expressão das pessoas, caracterizando uma espécie de tensão entre produções de sentidos e o que se tomam como socialmente reconhecido. Por essa ótica, a constituição do homem como sujeito passa, então, pela capacidade de aquele primeiro posicionar-se de maneira ativa e criativa no âmbito dos diferentes espaços sociais, tornando-se, assim, um agente de transformação do mundo em que vive (GONZÁLEZ REY, 2003).

Em linhas gerais, concorda-se com a concepção de lugar como um produto social (LEFEBVRE, 1991). Como este autor coloca, o lugar é definido de maneira objetiva, embora também se manifeste por meio de aspectos mentais ou cognitivos. Para ele, o lugar (ou espaço social, como referido em sua obra) nunca é "vazio", porque incorpora significados e sentidos para os atores que nele estabelecem (ou estabeleceram) suas ações. O lugar pode ser físico, geográfico, mas é, além disso, uma metáfora para um conjunto de sentimentos, interpretações, memórias dos sujeitos em relação àquela espacialidade.

O lugar como um dos pilares da ação humana não é absoluto, não está fechado em si mesmo, não é restrito aos limites físicos. Ao contrário, por se configurar como uma arena de interações entre os sujeitos, incorpora, também, a relação com outros lugares. O lugar organização, por exemplo, se insere no lugar sociedade, no lugar mundo (CHANLAT, 1996; SPINK, 2001; RICHARDSON e JENSEN, 2003). Nesse sentido, o que assume importância quando se trata dessa noção de lugar como socialmente construído é a possibilidade de coexistência de inúmeros lugares em um único ambiente físico (FLYVBJERG e RICHARDSON, 1998) pelo fato de os sujeitos conferirem diferentes significados e sentidos aos mesmos objetos e formas geométricas do espaço (TAYLOR e SPICER, 2007), bem como aos elementos discursivos que sustentam esses objetos e formas geométricas do espaço, o que se dá também na prisão.

\section{O discurso da reinserção social na prisão: construção de realidades ou utopias?}

Foucault (1977) defende que a emergência da pena prisão corresponde ao período em que os mecanismos institucionais que davam forma e faziam funcionar uma sociedade de soberania foram reajustados a fim de fazer valer as premissas de uma sociedade disciplinar, de vigilância. No final do século XVIII e início do século XIX, no bojo de transformações sociais e econômicas, está a noção de um novo tipo de exercício de poder, capilarizado, que atravessa todo corpo social, diferente, portanto, do poder como algo centralizado e personificado na figura do monarca. A instauração de uma nova "economia" do poder deixaria suas marcas na forma de tratar aqueles sujeitos cujo comportamento não se mostrava consoante aos códigos sociais que vigoravam na época (FOUCAULT, 1977; 1992).

Não mais os castigos físicos concebidos para a obtenção de sofrimentos excessivos, não mais a exposição desses sofrimentos em locais públicos e, por decorrência, não mais a espetacularização da dor. O patíbulo e 
todo o teatro punitivo dão lugar ao cumprimento das penas em "[...] uma grande arquitetura fechada, complexa e hierarquizada que se integra no próprio corpo do estado" (FOUCAULT, 1977, p. 103). O encarceramento do criminoso nessa arquitetura constitui um dos marcos da passagem da punição nos moldes dos regimes monárquicos à vigilância da sociedade disciplinar, em que o exercício do poder se desvincula do conceito negativo de repressão, de total apropriação, para se alinhar aos aspectos do que seria classificado como adestramento. $\mathrm{O}$ castigo e a correção que engendra circunscrevem-se à relação entre o prisioneiro e os que o vigiam, fundada nos processos de transformação e controle dos sujeitos, processos que se situam como condição e consequência da formação de um saber acerca dos sujeitos simultaneamente (FOUCAULT, 1977; 1992).

As técnicas, os vários discursos de teor apreciativo, sejam diagnósticos, prognósticos, ou normativos, delineiam um estatuto de verdade que se inter-relaciona com a prática do poder de punir. O que se observa aqui é o entrelaçamento do poder e do saber, um incidindo sobre o outro ou, mais precisamente, quem exerce o poder cria objetos de saber, sendo a recíproca também é verdadeira, isto é, o saber provoca efeitos de poder, quando usado um conjunto acumulado de informações, de conhecimentos (FOUCAULT, 1977; 1992).

A prisão, uma instituição total (GOFFMAN, 1961), passa a ser o lugar dos que cometeram atos desviantes ou criminosos. Um lugar entre o mundo da criminalidade e o restante do mundo social (CUNHA, 2010) que, em sua acepção moderna, é legitimado pelo discurso da recuperação, da correção para a reinserção social do sujeito. Não obstante o cumprimento da pena de reclusão nos regimes fechado, semiaberto e aberto com as particularidades das legislações pertinentes (BRASIL, 1984), e dos espaços sociais em que se cumpre a pena (penitenciárias, centros de ressocialização, cadeias públicas, hospital de custódia e tratamento psiquiátrico etc.), assume-se a lógica criminoso-paciente, a premissa de que o sujeito seria reeducado, recuperado, e preparado, por conseguinte, para a sua futura reinserção na sociedade (CABRAL, 2006; MAIA, SÁ NETO, COSTA et al., 2009).

Mas até que ponto as organizações prisionais são espaços sociais para a ressignificação de condutas, espaços para a reedição de histórias e de projetos de vida? Martins (2008) e Cunha (2010) consideram que a ressocialização entre muralhas somente legitima a política pública de controle e repressão dos desviantes. Para Cunha (2010), imputar às prisões um papel pedagógico é o mesmo que insistir em uma visão mistificadora, pois elas não são espaços de cuidado e de proteção dos criminosos. Tudo não passaria de uma retórica que serve, por um lado, ao propósito do Estado de controlar uma massa de sujeitos que constituem apêndices inúteis da sociedade (TAVARES e MENANDRO, 2008) e, por outro, para atender ao objetivo dessa última de se ver separada e protegida dos que são "perigosos" (CUNHA, 2010).

A incoerência caracterizaria os discursos produzidos e as técnicas utilizadas nesse espaço de encarceramento destinado aos que transgrediram leis, aos que descumpriram um suposto pacto social (SEQUEIRA, 2006), enfim, aos que foram expulsos da sociedade (ESPINOZA, 2004). O ordenamento jurídico, a Lei de Execução Penal (BRASIL, 1984), por exemplo, é construído sob a máxima de uma terapêutica prisional que visa propiciar a reeducação e ressocialização do preso. Todavia, levam o nome de "reinserção" processos que, em sua essência, remetem ao preceito da exclusão. Isso pelo fato de, nas prisões, os mecanismos institucionais se articularem no desenho de uma lógica que apenas segrega, separa e coloca os sujeitos à mercê de um sistema de relações em que as categorias inferior (os segregados) e superior (os segregadores) aparecem bem delimitadas. Ao sujeito encarcerado resta o lugar do diferente, isto é, o apenas estar em um mundo sem dele fazer parte (ESPINOZA, 2004; SEQUEIRA, 2006). Resta a encarnação do estigma ${ }^{6}$ (GOFFMAN, 2008), mais precisamente, do "criminoso" e o enfrentamento dos preconceitos ao retornar ao convívio em sociedade (BASTOS, 1997).

${ }^{6}$ É um termo que remete à ideia de não aceitação social. Porém, apesar de aludir a certo atributo depreciativo, é preciso considerar que o estigma tem sua origem em uma linguagem de relações sociais, pois um atributo pode servir ou não para a estigmatização de um sujeito dependendo do meio social considerado (GOFFMAN, 2008). 
Sequeira (2006) então acredita que reeducação e ressocialização são palavras da lei vazias de sentido ou, pelo menos, esvaziadas do sentido que legitima o aprisionamento. Para ela, a metáfora do "estrangeiro" é adequada para representar o sujeito criminoso, pois este é o desconhecido (e/ou desconsiderado) pelos outros, e é o desconhecido por si mesmo, já que ocorre a (ou pelo menos, empreende-se uma tentativa de) apropriação de todos os aspectos de sua vida, o completo aprisionamento de seu ser. Assim, como espaço físico, de modo geral, a prisão rompe, separa do contexto social global. No entanto, enquanto espaço social, como um lugar, a prisão erige-se em experiências e representações que, normalmente, esboçam uma face caricaturada de vários aspectos que se desenrolam na sociedade maior (CASTRO, 1991; ESPINOZA, 2004). Tal como se percebe em outros espaços sociais, nesse lugar também se insiste em uma espécie de inclusão, ao mesmo tempo em que são operadas divisões ou categorias; em outras palavras, se insiste em incluir, excluindo (SEQUEIRA, 2006).

\section{Metodologia}

Com base no objetivo, fez-se a opção pela estratégia de pesquisa de cunho qualitativo e pela técnica do estudo de caso. Em uma pesquisa qualitativa, os esforços se voltam para uma compreensão sobre a natureza particular dos fenômenos (ou objetos) e das relações que estabelecem, sendo tal natureza delimitada por algumas regularidades, mas também (e principalmente) pela complexidade, inconstâncias e contradições (GODOY, 1995; FLICK, 2004; CHIZZOTTI, 2005). Nesse estudo, a pesquisa qualitativa se mostra adequada por valorizar a perspectiva dos sujeitos no que tange a um fenômeno específico em que aqueles estão envolvidos. Nessa pesquisa não importa o estudo de situações passíveis de serem reproduzidas em contextos artificiais de "laboratório", mas as implicações engendradas pelas distintas práticas e interações dos sujeitos em um espaço social peculiar. Interessa a análise acurada do ambiente natural de determinado fenômeno, isto é, o contato com o espaço social em que ocorre e do qual é parte (FLICK, 2004).

Sobre o método de estudo de caso, Yin (2005) assinala que se caracteriza pela investigação profunda de fenômenos contemporâneos inseridos em determinados contextos da realidade, principalmente quando os limites entre fenômeno e contexto são pouco discerníveis. Assim, é pertinente na medida em que o pesquisador busca uma compreensão minuciosa das dinâmicas características de contextos singulares (EISENHARDT, 1989), sobretudo quando essas dinâmicas remetem às relações de uma miríade de elementos (STAKE, 1978).

O estudo de caso foi desenvolvido em uma das unidades femininas da Associação de Proteção e Assistência aos Condenados (APAC), entidade civil, sem fins lucrativos, com personalidade jurídica própria, cujos intentos precípuos são "Recuperar o Preso", "Proteger a Sociedade", "Socorrer a Vítima" e "Promover a Justiça" (OTTOBONI, 1997; 2001). O centro de ressocialização que foi a unidade empírica dessa pesquisa, foi inaugurado em 26 de julho do ano de 2002, em Itaúna, em Minas Gerais. Sem a presença de policiais militares, policiais civis ou de agentes penitenciários, tal organização atualmente funciona no prédio que outrora existia a unidade masculina. 22 mulheres vivem na APAC feminina, cumprindo sentenças nos regimes aberto, semiaberto ou fechado. Nessa organização, o discurso da possibilidade de recuperação (e, da possibilidade de reinserção social) é tão forte que, como já dito, "recuperando" é a palavra "correta" para designar os sujeitos que cumprem penas de reclusão.

A coleta dos dados, que ocorreu entre setembro e outubro de 2011, foi feita por meio 15 entrevistas semiestruturadas. Com duração média de 50 minutos, cada depoimento foi gravado e transcrito na íntegra. Decidiu-se manter o anonimato dos sujeitos entrevistados, identificando-os pelos códigos E-1, E-2, por exemplo, e pela menção ao regime de cumprimento das penas (fechado, semiaberto e aberto) de cada um dos sujeitos.

De acordo com a premissa de que, por meio das práticas discursivas, compreender-se-á a produção de sentidos que se desenvolve na dinâmica das relações sociais historicamente constituídas e culturalmente 
localizadas (SPINK e MEDRADO, 1999), para interpretar o material coletado, adotou-se a técnica de análise do discurso, em sua vertente francesa. Como definido por Maingueneau (1998, p. 13), semelhante técnica não se limita a uma análise linguística do texto em si ou, por outro lado, a uma análise sociológica ou psicológica do seu contexto. É um instrumento que "[...] visa a articular sua enunciação sobre um certo lugar social". Adotar essa técnica passa pelo reconhecimento de que a linguagem não se configura como um universo de signos formais ou como uma entidade abstrata e neutra que serve apenas como meio de comunicação. Linguagem é, na instância dos discursos, modo de interação, modo de produção social e, portanto, lugar da manifestação da ideologia (BRANDÃO, 2002).

O processo de análise dos dados envolveu, de início, a leitura das entrevistas, o que possibilitou o destaque de alguns fragmentos discursivos ${ }^{7}$. Em seguida, procurou-se delimitar categorias discursivas a que os tais os fragmentos faziam alusão. As categorias estabelecidas foram: a) cada "recuperanda" no "seu" lugar; b) lugares e subjetividades; c) diferentes lugares e produções de sentidos sobre o discurso da reinserção social. Depois, foram agrupados os fragmentos discursivos conforme a aderência às categorias discursivas e, uma vez agrupados, sublinharam-se trechos específicos, os quais foram analisados tendo em vista as seguintes estratégias discursivas de persuasão ideológica ${ }^{8}$ : a) análise lexical; b) identificação e análise dos principais temas e figuras (explícitos ou implícitos) dos discursos; c) análise dos principais discursos; d) análise dos aspectos interdiscursivos; e) análise dos principais aspectos ideológicos defendidos no discurso; f) análise dos principais aspectos ideológicos combatidos no discurso; g) posição do discurso hegemônico em cada um dos textos, em relação aos discursos hegemônicos na sociedade em que eles se situam.

\section{Apresentação e análise dos dados}

Nesta seção, são apresentados e discutidos os dados obtidos a partir das entrevistas. Da análise desse material, destacaram-se algumas categorias discursivas: a) cada "recuperanda" no "seu" lugar; b) lugares e subjetividades; c) diferentes lugares, diferentes produções de sentidos sobre o discurso da reinserção social, a seguir apresentadas.

\section{Cada "recuperanda" no "seu" lugar}

Fischer (1994) afirma que, nas organizações, os espaços são divididos, impostos e controlados levando-se em conta determinados princípios do que se chamaria de modelo de racionalidade. Complementando essa ideia, poder-se-ia dizer que a "arrumação" dos espaços sociais ou lugares seria explicada e, por decorrência, justificada, a partir de determinados discursos. Os fragmentos discursivos (01), (02) e (03) elucidam alguns aspectos atinentes a essa "arrumação" que ocorre na organização prisional pesquisada.

(01) Tem as meninas do aberto que ficam ali e a gente não pode ter contato com elas. Porque elas estão indo para a rua e então a gente não pode ter contato com elas não [...] Se as meninas tiverem sentadas ali a gente não pode nem passar perto. Porque é bom para nós, porque qualquer coisa de errado que aparecer aí a gente que paga né. Vamos supor, elas trabalham na rua, se, vamos supor, trazem uma fofoca da rua, ou alguma coisa errada porque elas vem lá da rua né, e se a gente tiver contato com elas a gente leva também.

${ }^{7}$ Fragmento discursivo se refere a um trecho selecionado da entrevista, em que se destaca algum elemento que se deseja observar.

8 "A finalidade última de todo ato de comunicação não é informar, mas persuadir o outro a aceitar o que está sendo comunicado. Por isso, o ato de comunicação é um complexo jogo de manipulação com vistas a fazer o enunciatário crer naquilo que se transmite. Por isso, ele é sempre de persuasão. Nesse jogo de persuasão, o enunciador utiliza-se de certos procedimentos argumentativos visando a levar o enunciatário a admitir como certo, como válido o sentido produzido. A argumentação consiste no conjunto de procedimentos linguísticos e lógicos usados pelo enunciador para convencer o enunciatário" (FIORIN, 2005, p. 75). 
Por isto que eles preservam a gente de não ficar perto para não prejudicar a nós mesmos (E-1; regime semiaberto).

A enunciadora do discurso (01), sugere a existência de espaços específicos para as "recuperandas" do regime aberto e semiaberto por meio de uma interdiscursividade entre sujeitos ("as meninas do regime aberto" versus "a gente") $)^{9}$. O implícito subentendido divide as "recuperandas" em duas categorias: quem está indo para a "rua" e quem não está, sendo possível identificar o posicionamento ideológico da enunciadora sobre a "rua". "Estar na rua" sugere possibilidades de cometer novos crimes, conforme a seleção lexical "porque qualquer coisa de errado que aparecer aí a gente que paga né". A separação das "recuperandas" do regime aberto, na visão de quem fala, é pertinente pois, como é explícito, "[...] elas vem lá da rua né". A interdiscursividade ${ }^{10}$ permeia ainda a ressignificação do léxico "rua". A "rua", figura que remete ao tema do perigo e ao discurso da reincidência, contrasta com o tema proteção oferecida pela própria organização na figura da equipe dirigente ("eles"), tema este que, por seu turno, relaciona-se ao discurso da recuperação e da reinserção social. Permanecer na APAC significa que o sujeito estaria protegido, alheio às possibilidades de "desvios". A ideia de perigo está tão associada com a figura da rua que se utiliza o léxico "preservam" para confirmar a necessidade de separação das "recuperandas" do regime aberto.

(02) Porque o regime fechado não pode ter contato com o semiaberto e nem o semiaberto com o aberto. Pelo fato do aberto já está na rua. E então o aberto não pode trazer notícia ruim da rua para o semiaberto e o semiaberto não pode passar para o fechado. E pode ser que tragam alguma coisa, e o semiaberto passa para o fechado, vai prejudicar todos os regimes, todas as presas. [Mas, notícia ruim?] É, do mundo lá fora, sobre, por exemplo, se por um acaso tiver uma recuperanda aqui que pode estar fazendo coisas erradas lá fora $(\mathrm{E}-5$; regime fechado).

No fragmento discursivo (02), chamam a atenção duas seleções lexicais: “[...] não pode trazer notícia ruim da rua" e "[...] É, do mundo lá fora, sobre, por exemplo, se por um acaso tiver uma "recuperanda" aqui que pode estar fazendo coisas erradas lá fora". A interdiscursividade se faz presente entre os discursos da reincidência (ou da sua possibilidade, no caso das recuperandas que saem da APAC) e da recuperação (aparentemente efetiva para as mulheres que nessa instituição permanecem). Como lembra Fischer (1994), a arrumação dos espaços organizacionais, ou a "fixação" de objetos e sujeitos em um dado meio social estabelecem ou orientam as vias de circulação, os canais formais de comunicação. No caso da APAC, impõem-se espaços distintos para o controle de acesso a informações ("notícia ruim da rua"). Esse léxico se refere aos casos de "recuperandas" que, "fora" da prisão (por já terem cumprido suas penas ou por saírem para trabalho externo), persistiram em atividades criminosas. Ora, "notícias" desse cariz não convergem com a imagem de uma organização "protetora" que abriga sujeitos "recuperandos", que readquirem algo perdido.

(03) No aberto você fica sabendo de tudo, e aqui, no fechado, a gente não fica sabendo de nada. [Sabendo de tudo o quê?] Uai, do que acontece, tipo a administração, do que acontece lá em cima, lá fora, e como elas estão no aberto e aqui é o fechado, elas vão falar com a gente e aí não pode. E eu acho que é isso mesmo, é como eles falam né, é melhor ficar cada recuperanda no seu lugar, cada uma no seu regime (E-2; regime fechado berçário).

${ }^{9}$ Nem todos os sujeitos que cumprem pena em um regime semiaberto possuem o direito a trabalho externo. Na unidade prisional estudada, as recuperandas do regime semiaberto auxiliam apenas em alguns trabalhos internos (atender telefone, recepcionar visitantes, por exemplo).

${ }^{10}$ Compreender a interdiscursividade passa, primeiramente, pela apreciação do conceito de intradiscurso. Como estabelece Faria (2001), o intradiscurso se refere à trajetória de sentidos que é desenvolvida ao longo do texto. Já o interdiscurso, é constituído pela oposição, pela contradição a essa trajetória de sentidos identificada quando da caracterização do intradiscurso. 
No que tange ao fragmento discursivo (03), repete-se a interdiscursividade entre "lá", no aberto, onde "você fica sabendo de tudo" e "aqui", no fechado, em que "a gente não fica sabendo de nada". Pela seleção lexical "E eu acho que é isso mesmo, é como eles falam né, é melhor ficar cada "recuperanda" no seu lugar, cada uma no seu regime", observa-se a reflexão e a refração linguísticas. Reflete-se um dos princípios do sistema penitenciário, que já é inclusive regulamentado pelos aparatos legais e normativos (BRASIL, 1984): a diferenciação de regimes de execução das penas privativas. Ao mesmo tempo, implicitamente refrata-se a condição das "recuperandas", que precisam ficar "cada uma em seu lugar" para que a tentação não as faça infringir a lei; isto é, para evitar "problemas", é melhor que fiquem separadas. No mesmo trecho, identificase a interdiscursividade entre o discurso dos dirigentes da APAC ("eles"), que implicitamente se assume como "correto", e o cotidiano de "recuperandas" que não saberiam o que é bom para si próprias. O discurso hegemônico é incorporado e reproduzido pelo discurso da "recuperanda", legitimando a sua opinião sobre a divisão dos lugares "acessíveis" ou "proibidos" (e, por extensão, das pessoas com as quais se pode ou não construir relacionamentos), o que converge com a lógica organizativa do sistema penitenciário como um todo. Lógica que, como observa Foucault (1977), se baseia na repartição dos sujeitos nesta ou naquela categoria, viabilizando as condições para uma espécie de formação de um saber sobre os sujeitos e, assim, um controle sobre eles.

\section{Lugares e subjetividades}

O lugar é, essencialmente, um produto social. Caracteriza-se por certa materialidade ou objetividade de artefatos físicos. Mas, para que um dado espaço seja considerado um lugar é necessário que os sujeitos produzam significados e sentidos sobre os objetos e traçados geométricos do espaço (LEFEBVRE, 1991; TAYLOR e SPICER, 2007). O lugar possui, assim, um conjunto de elementos concretos e simbólicos. De forma geral, os fragmentos discursivos (04), (05) e (06) trazem alguns desses elementos concretos e simbólicos presentes na APAC.

(04) Aqui no berçário também é fechado só que não tem grade, não tem aquela cela no céu que tem lá do outro lado onde as outras meninas estão. Aqui a gente se sente mais em casa. E para vir para este lado aqui tem que ter muito mérito, tem que ser bem comportada. Se tiver alguma coisa errada não deixa vir não, e também ficar né. Foram eles que me chamaram para vir para cá [...] Nossa, lá tem grade. Aqui, tem janelas, porta. Lá, a gente tem que ficar só dentro daquele quadrado e às 10 horas da noite trancam a cela. Aqui também fecham a porta às 10 horas da noite. Mas tem esse espaço, e é como se a gente tivesse dentro de uma casa. Aqui para mim é uma casa, parece com a minha casa, só fica faltando minha família. Apesar de a gente estar presa, aqui a gente se sente mais gente (E-3; regime fechado - berçário).

(05) Nós estamos aqui no berçário é porque nós temos um comportamento bom. E aí eles deixam. Igual eu sou a mais velha da turma toda, eles me deram esta facilidade de ficar aqui no berçário que é mais tranquilo. Porque das meninas todas eu sou a mais velha, a mais antiga, e então a gente já tem mais tempo, e ai eles deixam eu ficar aqui porque é mais tranquilo. Aqui é tranquilo. Aqui é diferente, por causa que aqui não tem grade, não tem cela e lá do outro lado que você viu tem. Então lá a gente fica mais presa. É esquisito né, tudo com grade. Aqui pelo menos tem a área, não tem a grade. É igual a mim te falei, aqui eu me sinto como se eu estivesse em casa. Lá do outro lado, não. Nossa, eu chorava demais lá, menina (E-2; regime fechado - berçário).

Considerando os três fragmentos discursivos, a "grade" e a "cela" são as figuras que se relacionam ao tema aprisionamento (ou sofrimento na prisão), ao passo que o tema da dignidade (ou do ambiente "familiar") surge nas figuras "porta" e "janelas". A enunciadora do discurso (04) fala das diferenças que marcam os lugares das "recuperandas" do regime fechado nas instalações do berçário. E, no desenrolar dessa interdiscursividade, delimita dois grupos, o de "recuperandas do outro lado", onde existem "grade" e "cela"; 
e o das "deste lado", que estão no berçário, em que portas e janelas compõem a estrutura física do lugar. Para além dos elementos mais concretos (a porta e a janela), a enunciadora produz sentidos (GONZÁLEZ REY, 2005) sobre tais elementos fazendo com que aquele espaço social se aproxime da própria casa, conforme a seleção lexical "Aqui para mim é uma casa, parece com a minha casa, só fica faltando minha família". As diferenças concretas e simbólicas entre os lugares se estendem às palavras que caracterizam ações neles realizadas. Um mesmo procedimento, o de recolher as "recuperandas" em determinado horário, produz sentidos distintos, dependendo das condições sociais de produção do discurso; se se fala a partir do berçário ou não: no berçário, "fecham a porta"; nas demais instalações do regime fechado, "trancam a cela".

Ainda no fragmento discursivo (04), destaca-se a seleção lexical "apesar de a gente estar presa, aqui a gente se sente mais gente". A enunciadora reproduz um discurso hegemônico em muitos contextos sociais, que desqualifica o sujeito encarcerado, que o coloca como alguém inferior, destituído das características humanas. Nessa perspectiva, o encarcerado que cumprisse sua pena em um lugar a partir do qual a "recuperanda" fala, isto é, o berçário, se perceberia como "mais" humano, como alguém com "mais" dignidade.

O lugar produz e reproduz modos de ser humano, o lugar potencializa ou não a ação individual (FISCHER, 1994; VALADARES, 2000; HALFORD e LEONARD, 2006). Quando se está no regime fechado, como é notado nos discursos (04) e (05), o cumprimento da pena privativa no berçário exige que a "recuperanda" apresente uma conduta adequada, condizente com as regras da organização. É necessário esclarecer que o direito de permanecer no berçário é concedido às "recuperandas" gestantes e a outras escolhidas pela equipe dirigente a partir de critérios relacionados ao comportamento, por exemplo. Os lugares são concedidos, e tal concessão reforça o modelo disciplinar. No discurso (04), conforme a seleção lexical "para vir para este lado aqui tem que ter muito mérito, tem que ser bem comportada. Se tiver alguma coisa errada, não deixa vir não, e também ficar né". No discurso (05), seleção lexical semelhante é: "Nós estamos aqui no berçário é porque nós temos um comportamento bom. E aí eles deixam". É sobretudo no fragmento discursivo (05) que a enunciadora, usando as figuras da "grade" e da "cela", evidencia interdiscursivamente o tema do aprisionamento (ou do sofrimento na prisão): no "outro lado", ela se sentia "mais presa" e "chorava demais". O implícito subentendido é que "aqui" ela chora menos e se sente menos presa. Trata-se, assim, de outro lugar, que produz sentidos diferentes do anterior.

(06) Aqui no semiaberto você está mais livre do que lá embaixo. Livre, porque você tem acesso à porta, você tem acesso ao telefone. Aqui você trabalha um pouco menos do que lá embaixo, porque lá é muito mais coisas para fazer. Aqui você fica atendendo telefone. Anotando recado, abrindo a porta e fechando a porta. E então é menos serviço. Mas, porém, para você fazer uma besteira é muito fácil. Então te dá mais liberdade, mas, porém, a tentação é maior (E-6; regime semiaberto).

No que tange ao fragmento discursivo (06), a seleção lexical "aqui no semiaberto você está mais livre do que lá embaixo" é destacada por explicitar, mais uma vez, a diferença entre os lugares quando se trata da sensação de liberdade. A enunciadora, que cumpre sua pena no regime semiaberto, utiliza a expressão "lá embaixo" para se referir ao lugar do regime fechado. A seleção lexical "lá embaixo" assume concretude de figura na medida em que os espaços do regime semiaberto estão localizados na parte superior do edifício e os do regime fechado, na parte inferior. Essa expressão também incorpora um significado simbólico de progressão das penas de reclusão, do sujeito estar mais próximo ou não de seu retorno à sociedade. Estar nos espaços sociais próprios do regime semiaberto parece significar, sim, estar mais livre; mas, também quer dizer maior facilidade para "fazer uma besteira", significa que "a tentação é maior". Significa, portanto, a possibilidade de reincidência, e de adiamento na reinserção social. 


\section{Diferentes lugares e produções de sentidos sobre o discurso da reinserção social}

Os lugares na organização se apresentam como um conjunto de discursos que modela hábitos de pensamentos ao legitimar objetos de conhecimentos, posições e ações dos sujeitos (CHIA, 2000; HARDY, PALMER e PHILLIPS, 2000). Tais discursos legitimam, sobretudo, a existência da própria organização, sendo um exemplo as prisões e, por extensão, o discurso da reinserção social dos encarcerados. No caso da APAC, o discurso da possibilidade de reinserção é tão forte que "recuperando" é a palavra considerada correta para a designação dos sujeitos que cumprem pena nos regimes fechado, semiaberto e aberto. Mas, como esse discurso é ressignificado pelos diferentes sujeitos? Os discursos (07), (08) e (09) contém elementos que permitem iniciar uma reflexão sobre o referido questionamento.

(07) Mas, hoje, não porque eu estou presa, não é porque eu vivo dentro de uma cela, mas eu tenho minha cabeça no lugar, é porque já está na hora né. Eu vou sair daqui como se fosse com 16 anos, com sede assim de começar a vida, de começar a estudar, vou trabalhar, vou ajudar, vou dar o mundo pra minha família, porque eles merecem, e, poxa, eu também mereço ter uma vida normal. Voltar, voltar e esquecer o passado. O passado pra mim passou. [...] Eu vou ser uma mãe de verdade, eu vou trabalhar, assim, vou ser uma pessoa digna né, como a gente aprende aqui na APAC (E-8; regime fechado)

Nos fragmentos discursivos (07), (08) e (09), destacam-se discursos referentes a duas dimensões temporais: passado e futuro. Especificamente no depoimento (07), o passado é um tema que alude ao discurso do erro, da criminalidade. É um discurso ideologicamente combatido, pois fala-se em "esquecer o passado". Em contrapartida, o tema "vida normal" está relacionado ao discurso da esperança de recuperação ou da reinserção social, sendo semelhante discurso sustentado, principalmente, pelos léxicos "estudar" e "trabalhar", os quais compõem a sintaxe discursiva. Na seleção lexical "[...] e, poxa, eu também mereço ter uma vida normal", a enunciadora reproduz um discurso veiculado na sociedade de que o sujeito encarcerado é “diferente" (ESPINOZA, 2004; SEQUEIRA, 2006), um apêndice inútil (TAVARES e MENANDRO, 2008), por não se enquadrar no que se convencionou chamar de "vida normal". E ela, a enunciadora, se coloca em uma categoria dos que ainda não possuem uma vida normal, mas que a merecem. As personagens do discurso são a "mãe de verdade" e a "pessoa digna", que inclusive se situam em um futuro legitimado pela reinserção social. Mais precisamente, a sintaxe discursiva "eu vou ser uma mãe de verdade, eu vou trabalhar, vou ser uma pessoa digna né, como a gente aprende aqui na APAC" sugere o que a organização considera e reproduz como digno.

(08) Quando eu for para o semiaberto e ganhar o direito de trabalho externo, eu vou trabalhar, ficar com a mente firme, ficar bem longe dos falsos amigos. E quando eu sair de vez daqui, eu vou ter uma vida totalmente diferente, levar uma vida digna. Aqui na APAC eles trabalham muito com a gente isso. E, sabe, eu era tranquila. Por que eu não posso ser de novo? Por que eu não posso voltar a ser normal como eu era antes? Quero voltar a ter a vida que eu levava, como era antes de 2002 pra 2003 (E-14; regime fechado).

O fragmento discursivo (08) também relaciona o tema "vida normal" ao discurso da reinserção social e, da mesma forma, por meio de uma interdiscursividade implícita, sugere que a vida que se leva no cárcere não é normal, e que se está "fora" da sociedade. Tal como no discurso (07), a promessa ou esperança do trabalho assume centralidade no processo de reconstrução da realidade do encarcerado. A enunciadora afirma explicitamente que, quando estiver no semiaberto e com o direito de saída para fins de trabalho, manterá a "mente firme". Mediante essa expressão, veicula-se a concepção de que o sujeito que comete atos criminosos, ou quem reincide nesses atos, sofre de algum desajuste psíquico. O implícito pressuposto é de "fragilidade mental". O implícito subentendido é que "reajustar-se" socialmente é não sucumbir às tentações, e que todo reincidente é um "fraco". Dois silêncios importantes e relacionados se referem ao altruísmo da sociedade e ao peso do indivíduo no processo de reinserção. Silencia-se sobre o preconceito a que a enunciadora se sujeitará ao sair da prisão, isto é, conta-se com a sociedade como franca apoiadora da nova fase na vida da "recuperanda". Ao mesmo tempo, o processo é centrado e só depende do sujeito, que precisa 
hoje seguir estritamente as regras na APAC, para que, amanhã, possa se "manter na linha". Não depende só dele apenas a ressocialização, e tampouco a sociedade é generosa para com ex-infratores, e sobre isso há um silêncio, produzido a partir do lugar em que a enunciadora se encontra.

É ainda interessante no depoimento (08), ao contrário do discurso (07), a emergência do tema "passado" no sentido de saudade de uma etapa da vida em que se era "normal", isto é, "não criminosa", um sujeito diferente. Enuncia-se então a possibilidade de "voltar a ser normal" como se "era antes". Essas seleções lexicais explicitam uma produção de subjetividade baseada no sonho do retorno à vida "legal", "normal", o que em parte acontecerá pelo aprendizado da obediência na APAC. Esse desejo também é recorrente no fragmento discursivo (09), por exemplo, na seleção lexical "eu vou voltar a ter a vida normal que eu tinha antes":

(09) Eu vou voltar a ter a vida normal que eu tinha antes, porque eu estudava, trabalhava. Minha vida não tinha nada a ver com o crime. Eu sempre tive uma vida normal, normal, sabe. Aí com o fato que aconteceu na minha vida, entendeu. Assim, foi muito bom pra mim a cadeia. Eu aprendi a viver. Se eu sair lá fora hoje, por exemplo, e aparecer algum obstáculo na minha vida, eu vou saber lidar com aquilo. Eu vou saber enfrentar os problemas de frente, não vou recuar. Então, assim, eu quero voltar a ser, eu quero ser melhor do que eu era. Eu quero ser feliz, ser feliz de verdade. Eu vou mudar. Quem passa pela APAC, só não muda de vida quem não quer. Porque a gente tem muita oportunidade (E-11; regime fechado).

O discurso da reincidência é combatido ideologicamente, de maneira implícita subentendida por quem enuncia o fragmento (09): "se eu sair lá fora hoje, por exemplo, e aparecer um obstáculo na minha vida, eu vou saber lidar com aquilo". Levando em conta as condições sociais de produção do discurso, o léxico "obstáculo" é uma metáfora das possibilidades de crime. Além de combater o discurso da reincidência, busca-se afastar, interdiscursivamente, tal discurso da imagem da APAC: é do sujeito a responsabilidade por não ter se reinserido socialmente, por não ter mudado de vida ("quem passa pela APAC, só não muda de vida quem não quer"). Observa-se uma contraposição do discurso da recuperação encerrado na figura da APAC com o discurso da reincidência sugerido pela não mudança de vida por parte do sujeito: a recuperação é institucionalmente compulsória; o erro, individualmente opcional.

Como já colocado, estar em um lugar específico implica a possibilidade de exercer ou não determinada prática discursiva (FOUCAULT, 2004), ou em outros termos, a possibilidade de os sujeitos explicitarem (ou deixar implícitos) os sentidos que produzem sobre seu "eu" individual e do modo como esse "eu" se insere nos espaços sociais diversos. A enunciação assume aspectos distintos considerando se o sujeito fala a partir dos espaços sociais do regime fechado (fragmentos 07, 08 e 09), do regime semiaberto (fragmento 10) ou regime aberto (fragmento 11).

(10) Eu falei um dia com o meu namorado, falei que o meu livro que era da minha vida, eu peguei na gaveta e fechei. Agora eu comecei outra fase da minha vida, como presa. Eu trabalhava num lugar de convivência de mulheres, em um hospital particular. Agora que eu estou no semiaberto eu já fico com medo de sair e todo mundo me olhar como expresidiária. Por exemplo, se eu estiver num lugar assim e puxar o meu nome vai ver que eu sou ex-presidiária. Então, a partir do momento que eu acabar de pagar a minha cadeia a minha vida não vai ser a mesma que era antigamente, como era antes de eu levar aquela droga pra ele no presídio. Mesmo pagando minha cadeia aqui na APAC, mesmo assim eu vou sair como ex-presidiária e isto ai vai me afetar demais. Eu vou sair rotulada como ex presa. Não tem como eu por uma pedra em cima de uma coisa tão grave que me aconteceu (E-6; regime semiaberto).

O fragmento discursivo (10) baseia-se, essencialmente, no tema do preconceito ou da estigmatização dos exencarcerados. A enunciadora traz à tona sua reflexão sobre as dificuldades de se reinserir na sociedade. $\mathrm{O}$ implícito subtendido na seleção lexical "[...] todo mundo me olhar como ex-presidiária" se refere ao 
julgamento, por parte da sociedade, a respeito de um sujeito que cometeu um crime e que, em função disso, permaneceu isolado em uma organização prisional. Mais do que o julgamento, o referido trecho sugere a emergência de problemas à atuação desse sujeito em espaços sociais que não os da prisão. Na seleção lexical "eu vou sair rotulada como ex-presa", o léxico "rotulada" explicita a consciência do estigma (GOFFMAN, 2008), sendo demonstrado um alinhamento da hegemonia combatida, a de discriminação, ao que é hegemônico na sociedade: o discurso da segregação de quem é "diferente". O léxico "rotulada" impõe um destino ao sujeito, um destino distante de tudo que se viveu antes da incursão nas atividades criminosas ("minha vida não vai ser a mesma que era antigamente"), sugerindo poucas possibilidades de escolhas (implícito pressuposto).

(11) E então tem horas que passa pela minha cabeça, antes eu tivesse no fechado. Eu preferiria ficar bordando aqui. Antes eu tivesse no fechado, porque este regime aberto é ilusão. É ilusão porque ninguém está cassando preso não, ninguém gosta de preso não. Preso é humilhado. Porque não nota que não é humilhado, que não é olhado com olho torto quem não quer. Eu arrependi de ter saído. Eu acho que quando a gente passa por um lugar deste, a gente tem é que sair da cidade e ir embora e começar nova vida. Para quem é mais novo já não é fácil, agora para mim que estou com 62 anos vai ser muito mais difícil. Porque para começo de conversa eu nunca tive uma carteira de trabalho. Nunca na minha vida, nunca trabalhei para ninguém [...] (E-7; regime aberto).

O mesmo tema central do discurso (10), preconceito ou estigmatização dos ex-encarcerados, está presente no discurso (11). No entanto, neste texto, a enunciadora fala de "dentro" do discurso, parece refletir sobre algo que já lhe aconteceu (isto é, que já foi "humilhada", "olhada com olho torto") e, isso é subentendido a partir do trecho "eu me arrependi de ter saído". No depoimento (10), o trecho "medo de sair" indica que o sujeito expõe apenas uma angústia, algo ainda não vivido. Prosseguindo, pela seleção lexical do fragmento discursivo (11) "[...] porque este regime aberto é ilusão", profere-se um discurso de resistência à parte do discurso que ampara o sistema penitenciário (BRASIL, 1984). Questiona-se, nesse sentido, a função pedagógica do regime aberto de viabilizar a (re)adaptação do sujeito ao meio social mais amplo. Porém, mais do que refletir sobre as dificuldades de reinserção social dos encarcerados, estar no regime aberto possibilita que a enunciadora reflita sobre as dificuldades de reinserção social dos encarcerados que são idosos ("para quem é mais novo já não é fácil, agora para mim que estou com 62 anos é muito difícil"), se colocando então como personagem desse discurso de uma chamada reinserção ilusória.

\section{Discussão e conclusão}

Nesse artigo se procurou analisar a articulação dos elementos concretos e/ou simbólicos do(s) lugar(es) que os sujeitos ocupam na organização com os aspectos relacionados ao modo como esses sujeitos produzem sentidos sobre si mesmos e sobre suas relações sociais. Para cumprir este objetivo, desenvolveu-se um estudo de caso em uma unidade feminina de um centro de ressocialização, tendo sido realizadas 15 entrevistas semiestruturadas em profundidade, material trabalhado por meio da análise francesa de discurso.

A análise dos dados permitiu identificar que a questão dos lugares, além de geográfica e social, é organizacional em seu sentido mais amplo. Não obstante ocuparem o mesmo espaço, "longe" da sociedade de quem infringiram as normas, as entrevistadas falam de lugares consideravelmente distintos, o que se traduz em práticas discursivas peculiares.

Estar no regime aberto e semiaberto constitui algo que diferencia substancialmente os sujeitos quanto ao lugar. O contato com o mundo externo em algum nível significa liberdade, e em três sentidos: a) ausência de controle de informações por parte da organização prisional, já que se vê além das grades com seus próprios olhos; b) a possibilidade de produzir subjetividade à luz de outros referenciais além do da organização prisional; e c) a possibilidade de tomar decisões por si próprio, inclusive quanto à adesão ao programa da organização. Os sujeitos em regime fechado, ao mesmo tempo em que desejam, temem o contato com o 
mundo exterior, por conta do lugar que ocupam ser povoado pelas imagens do exterior perigoso e ameaçador, da organização poderosa e protetora, e ainda do "recuperando" invariavelmente fraco. O perigo de reincidir no crime só existe para os que se aventuram fora das grades. A liberdade é algo desejado, mas perigoso, porque significa não contar plenamente com a proteção da organização. Como o sujeito é fraco, precisa ser protegido para poder ser ressocializado em condições adequadas. Seu livre arbítrio é, portanto, um perigo. Transforma-se, assim, a compulsoriedade da privação do convívio social em uma organização prisional em resignação e mesmo em agradecimento por tal organização "poupá-los da tentação".

O lugar é construído socialmente no âmbito da prisão a partir da materialidade concreta. A existência de grades, por exemplo, relembra às "recuperandas" de que estão privadas da liberdade, diferenciando-as das colegas que podem circular em ambientes sem tal artefatos. Mesmo cientes de que se encontram aprisionadas, estas chegam a enunciar que se trata de seu lar, um discurso comum em outros contextos organizacionais produtores de subjetividade". Isto é, que o ambiente organizacional mais "ameno" lhes devolve, em algum nível, sua humanidade aviltada por práticas organizacionais de ataques sistemáticos ao "eu", como ocorre em instituições totais (GOFFMAN, 1961). O mesmo espaço que segrega e estigmatiza também pode restituir a dignidade à medida que trata com humanidade as "recuperandas", mas isso não é acessível a todas: apenas as que merecerem poder usufruir essa condição, o que estabelece a competição por "comportamentos exemplares" na organização.

O lugar também é uma construção social a partir da ressignificação da temporalidade na prisão. Passado e futuro são inscritos em novas agendas, algo a esquecer e rejeitar no primeiro caso, algo a ser construído de uma forma "adequada", no segundo. O desejo de normalidade que permeia a vida futura se dá a partir da referência da organização prisional, que "ensina" o jeito "certo" de viver: suas regras, assim, constituem o modelo que deve ser seguido para que se tenha uma "vida boa" no futuro. Produz-se uma subjetividade, assim, empenhada no afastamento de qualquer menção ao livre arbítrio do passado que conduziu a erros, e com o compromisso de, no futuro, o sujeito submeter-se à lógica sedimentada cotidianamente na organização prisional $^{12}$. A ideia de autonomia é problemática porque o sujeito é fraco - forte é o monarca e seu sistema, a quem se deve obedecer (FOUCAULT, 1977); sem o suporte de normas a que deve se submeter, ele recairá em erro. Por isso, a normalidade é associada a elementos concretos como o trabalho, que é fonte de dignidade moral porque estabelece, entre outros aspectos, uma rotina segura, tal como na prisão. $O$ aprendizado da obediência remete o sujeito ao "ajuste social" e ao afastamento da prisão. "Desobedecer" é aproximar-se da possibilidade do crime. As opções são simplificadas e estigmatizam o sujeito.

As principais contribuições desse artigo estão associadas às suas possibilidades de transposição analítica para outros contextos que permitam, pois, a análise organizacional mais ampla. O lugar é, sim, uma construção social relacionada a uma condição formal, a artefatos e a significações específicas, porém, a partir da análise do que foi dito (e também, muitas vezes, silenciado) pelos sujeitos dessa pesquisa, pode-se depreender que, de maneira geral, as prisões sustentam-se em uma dinâmica de funcionamento que não difere tanto da racionalidade que permeia a gestão de organizações tomadas pela maioria da sociedade como convencionais (empresas privadas, por exemplo). Dizendo de outra forma, os resultados empíricos suscitam a reflexão sobre o fato de que a realidade nas instituições totais não se configura como algo tão "distante" da realidade que é construída no âmbito das grandes organizações capitalistas contemporâneas.

As organizações trabalham no sentido de produzir subjetividades alinhadas com o que interessa aos dirigentes, cerceando, para isso, sistematicamente, noções como autonomia e livre arbítrio. Enriquez (2001)

${ }^{11}$ Estudos como os de Saraiva, Pimenta e Corrêa (2004), com foco no setor têxtil, corroboram que a conversão da organização em "lar" é comum a vários contextos organizacionais.

12

2 O sujeito que tudo pode, que exerce plenamente seu livre arbítrio, não tem espaço em uma sociedade em que há um poder absoluto que submete os demais. É o poder do monarca a base da lógica prisional. Ressocializar os detentos para que tenham condições de reinserção na sociedade significa não apenas controlá-los, mas produzir subjetividades que legitimem a ordem, que se submetam ao poder do monarca (FOUCAULT, 1977). 
oferece uma explicação para o êxito alcançado no âmbito das diversas organizações quando os intentos se tornam a produção e o controle de subjetividades. O autor observa a necessidade fundamental de os indivíduos se lançarem na construção de processos identificatórios, os quais sejam capazes de propiciar orientações na vida ou um nível considerável de segurança narcísica. A religião, por exemplo, é um sistema de significações sociais que, de certa forma, "tranquiliza" o homem, dando-lhe uma "garantia" de não viver no puro arbitrário. O fato é que, no contexto da sociedade em geral, devido a um "mal-estar" ou um enfraquecimento em muitas das identificações sociais, as organizações têm, comumente, encarnado o papel de "instituição divina", de objeto de segurança narcísica.

Se as organizações modernas, especialmente as empresas privadas, constroem para e de si uma imagem que se enraíza em um imaginário, muitas vezes, de empresa cidadã, de lugar da excelência, de lugar de capitalização da necessidade de "juventude eterna" (via incorporação de novas técnicas, novos processos e novas práticas que aludem ao dinamismo, flexibilidade, transformação) (FREITAS, 2000), nas organizações prisionais tais como a deste estudo, um centro de ressocialização, o imaginário produzido parece ser o da organização "protetora" que livra os sujeitos encarcerados das "tentações" da rua, quais sejam, das oportunidades de incorrência de novos crimes.

No bojo dessa discussão, cabe problematizar uma questão que, muitas vezes, aparece destacada em discursos que se propõem reformistas do sistema penitenciário brasileiro, isto é, a questão de os centros de ressocialização constituírem modelos alternativos de execução penal. Tais centros podem ser "alternativos" na medida em que a maioria se forma a partir de uma gestão compartilhada entre Estado e alguma organização não-governamental. Isso porque se questiona o rótulo do alternativo (isto é, do que se apresenta como uma proposta mais eficaz de reintegração dos sujeitos que cometeram crimes) para centros de ressocialização em que, como se depreende de muitos depoimentos coletados, os sujeitos se mostram profundamente dependentes dos cuidados ou de uma espécie de proteção organizacional, sentindo medo e ainda um despreparo no que toca a uma futura ocupação de lugares diversos dos lugares de desviantes outrora ocupados na sociedade mais ampla.

Continuando o raciocínio sobre a "aproximação" entre as características de empresas privadas ou públicas e organizações como a que foi objeto desse estudo, pode-se afirmar que nas empresas privadas ou públicas, os funcionários convivem com a crescente individualização do fracasso no que tange ao alcance de metas (FREITAS, 2000); em centros de ressocialização como os da APAC, é, paulatinamente, introjetado nos sujeitos encarcerados princípios que reforçam um sentimento de responsabilização pela reincidência.

Todavia, para além de realizar uma aproximação entre os aspectos que caracterizam o conjunto de processos e práticas de uma organização dita comum e de um estabelecimento prisional, não se pode esquecer que o presente estudo contribui de maneira particular na medida em que suscita uma reflexão sobre até que ponto esses tais centros de ressocialização se apresentam como espaços sociais com condições que possibilitem ao sujeito a construção de novos modos de vida, e que tal sujeito possa, consequentemente, se declarar e ser declarado por diferentes atores sociais como alguém "ressocializado". Precisamente, a investigação aqui delineada oferece contribuições no sentido de se refletir, portanto, sobre as políticas ditas "alternativas". Essa primeira dimensão que, em sua essência, se refere às dinâmicas internas desses tipos de organizações prisionais, tem seus reflexos na sociedade mais ampla, haja vista o interesse da maioria dos indivíduos na diminuição dos índices de violência e de criminalidade ${ }^{13}$, índices que, muitas vezes, são compostos também

\footnotetext{
${ }^{13}$ Não se ignora aqui uma das hipóteses críticas de Michel Foucault no livro Vigiar e Punir, mais precisamente, a de que as prisões, ao invés de se conformarem como dispositivos de repressão e redução da criminalidade, se apresentam como espaços sociais de produção e organização da delinquência. Primeiro, na visão de Foucault (1977), o que se chamaria de controle da criminalidade seria nada mais do que uma repressão seletiva das ilegalidades, isto é, repressão das ilegalidades das classes inferiores. Ainda, no contexto da prisão, a produção de uma delinquência controlável se constituiria como um dos meios de vigilância dessa população. O autor explica, nesse caso, que polícia, prisão e delinquência são os termos de um circuito que não se interrompe, por exemplo, "a vigilância policial fornece à prisão os infratores que esta transforma em delinquentes, alvo e auxiliares dos controles policiais que regularmente mandam alguns deles de volta à prisão" (FOUCAULT, 1977, p. 248).
} 
pelos elevados números de reincidência. Ademais, a realização de estudos como este, em organizações que não as do tipo empresarial, traz implicações para a produção de conhecimento no campo da Administração, isso porque desafia o pragmatismo imediatista das soluções organizacionais comprometidas com o lucro, evocando um pressuposto que, muitas vezes, não é tão claro para determinados pesquisadores da área, o de que Administração é, sim, uma ciência social aplicada, mas não apenas para resolver os problemas das empresas, mas da sociedade.

\section{Referências}

BASTOS, M. Cárcere de mulheres. Rio de Janeiro: Diadorim, 1997.

BERGSTRÖM, O.; KNIGHTS, D. Organizational discourse and subjectivity: subjectification during processes of recruitment. Human Relations, New York, v. 59, n. 3, p. 351-377, período 2006.

BOJE, D. M.; OSWICK, C.; FORD, J. D. Language and organization: the doing of discourse. Academy of Management Review, v. 28, n. 4, p. 571-577, 2004.

BRANDÃO, H. H. N. Introdução à análise do discurso. 8. ed. Campinas: Unicamp, 2002.

BRASIL. Lei $\mathrm{n}^{\circ} 7.210$, de 11 de julho de 1984. Institui a lei de execução penal. Código Civil Brasileiro. Brasília: Presidência da República, 1984.

CABRAL, S. "Além das grades": uma análise comparada das modalidades de gestão do sistema prisional. 2006. Tese (Doutorado em Administração). Escola de Administração, Universidade Federal da Bahia, Salvador, 2006.

CASTRO, M. M. P. Ciranda do medo: controle e dominação no cotidiano da prisão. Revista USP, n. 9, p. 57-64, 1991.

CHANLAT, J.-F. O ser humano, um ser espaço-temporal. In: CHANLAT, J.-F. (Org.). O indivíduo na organização: dimensões esquecidas. v. 3. São Paulo: Atlas, 1996. p. 107-110.

CHIA, R. Discourse analysis as organizational analysis. Organization, v. 7, n. 3, p. 513-518, 2000.

CHIZZOTTI, A. Pesquisa em ciências humanas e sociais. 7. ed. São Paulo: Cortez, 2005.

CUNHA, E. L. Ressocialização: o desafio da educação no sistema prisional feminino. Caderno Cedes, v. 30, n. 81, p. 157-178, 2010.

EISENHARDT, K. Building theories from case study research. Academy of Management Review, v. 14, n. 4, p. 532$550,1989$.

ENRIQUEZ, E. O indivíduo preso na armadilha da estrutura estratégica. Revista de Administração de Empresas, v. 37, n. 1, jan. /mar., p. 18-29, 1997.

A interioridade está acabando? In: LÉVY, A. et al. Psicossociologia: análise social e intervenção. Belo Horizonte: Autêntica, 2001. p. 41-55.

ESPINOZA, O. A mulher encarcerada em face do poder punitivo. São Paulo: IBCCRIM, 2004.

FARIA, A. A. M. Interdiscurso e intradiscurso: da teoria à metodologia. In: MENDES, E. A. M. M.; OLIVEIRA, P. M.; BENN-IBLER, V. (Org.). O novo milênio: interfaces linguísticas e literárias. Belo Horizonte: FALE/UFMG, 2001. p. $31-37$.

FIORIN, J. Linguagem e ideologia. 8. ed. São Paulo: Ática, 2006. 
. Elementos de análise de discurso. São Paulo: Contexto, 2005.

FISCHER, G. N. Espaço, identidade e organização. In: CHANLAT, J.-F. (Org.). O indivíduo na organização: dimensões esquecidas. v. 2. São Paulo: Atlas, 1994. p. 81-102.

FLICK, U. Uma introdução à pesquisa qualitativa. 2. ed. Porto Alegre: Bookman, 2004.

FLYVBJERG, B.; RICHARDSON, T. In search of the dark side of planning theory. In: PLANNING THEORY CONFERENCE, Oxford, 3, 1998. Proceedings... City: Organization, 1998.

FOUCAULT, M. A arqueologia do saber. 7. ed. Rio de Janeiro: Forense Universitária, 2004.

Microfísica do poder. 10. ed. Rio de Janeiro: Graal, 1992.

Vigiar e punir: nascimento da prisão. Petrópolis: Vozes, 1977.

FREITAS, M. E. Contexto social e imaginário organizacional moderno. Revista de Administração de Empresas, v. 40, n. 2 , p. 6-15, 2000.

GODOY, A. S. Introdução à pesquisa qualitativa e suas possibilidades. Revista de Administração de Empresas, v. 35 , n. 2, p. 57-63, 1995.

GOFFMAN, E. Estigma: notas sobre a manipulação da identidade deteriorada. 4. ed. Rio de Janeiro: LTC, 2008.

Manicômios, prisões e conventos. São Paulo: Perspectiva, 1961.

GONZÁLEZ REY, F. Sujeito e subjetividade: uma aproximação histórico-cultural. São Paulo: Pioneira Thomson Learning, 2005.

GUATTARI, F.; ROLNIK, S. Micropolítica: cartografias do desejo. Petrópolis: Vozes, 1986.

HALFORD, S.; LEONARD, P. Place, space and time: contextualizing workplace subjectivities. Organization Studies, v. 27 , n. 5, p. 657-676, 2006.

HARDY, C.; PALMER, I.; PHILLIPS, N. Discourse as a strategic resource. Human Relations, v. 53, n. 9, p. 12271248, 2000.

LEFEBVRE, H. The production of space. Oxford: Blackwell, 1991.

MAIA, C. N. et al. Introdução: história e historiografia das prisões. In: MAIA, C. N. et al. (Org.). História das prisões no Brasil. Rio de Janeiro: Rocco, 2009. p. 9-34.

MAINGUENEAU, D. Termos-chave da análise do discurso. Belo Horizonte: UFMG, 1998.

MARTINS, J. S. A sociedade vista do abismo: novos estudos sobre exclusão, pobreza e classes sociais. 3. ed. Petrópolis: Vozes, 2008.

OTTOBONI, M. Ninguém é irrecuperável: APAC - a revolução do sistema penitenciário. São Paulo: Cidade Nova, 1997.

. Vamos matar o criminoso? Método APAC. São Paulo: Paulinas, 2001.

RICHARDSON, T.; JENSEN, O. B. Linking discourse and space: towards a cultural sociology of space in analysing spatial policy discourses. Urban Studies, v. 40, n. 1, p. 7-22, 2003.

SARAIVA, L. A. S.; PIMENTA, S. M.; CORRÊA, M. L. Dimensões do discurso em uma empresa têxtil mineira. Revista de Administração Contemporânea, v. 8, n. 4, p. 57-59, 2004. 
SEQUEIRA, V. C. Uma vida que não vale nada: prisão e abandono político-social. Psicologia: Ciência e Profissão, v. 26, n. 4, p. 660-671, 2006.

SPINK, P. O lugar do lugar na análise organizacional. Revista de Administração Contemporânea, v. 15, n. edição especial, p. 11-34, 2001.

; MEDRADO, B. Produção de sentidos no cotidiano: uma abordagem teórico-metodológica para análise das práticas discursivas. In: SPINK, M. J. (Org.). Práticas discursivas e produção de sentidos no cotidiano. São Paulo: Cortez, 1999. p. 41-61.

STAKE, R. E. The case study method in social inquiry. Educational Researcher, v. 7, n. 2, p. 5-8, 1978.

TAVARES, G. M.; MENANDRO, P. R. M. Modos de vida de internos do sistema penitenciário capixaba. Psicologia e Sociedade, v. 20, n. 3, p. 340-349, 2008.

TAYLOR, S.; SPICER, A. Time for space: a narrative review of research on organizational spaces. International Journal of Management Reviews, v. 9, n. 4, p. 325-346, 2007.

VALADARES, J. C. Qualidade do espaço e habitação humana. Ciência e Saúde Coletiva, v. 5, n. 1, p. 83-98, 2000.

VAN DIJK, T. A. Ideology: a multidisciplinary approach. London: Sage, 1998.

YIN, R. K. Estudo de caso: planejamento e métodos. 3. ed. Porto Alegre: Bookman, 2005. 